\title{
Nano-ZnO Particles' Effect in Improving the Mechanical Response of Mg-3Al-0.4Ce Alloy
}

\author{
Sravya Tekumalla ${ }^{1}$, Najib Farhan ${ }^{1}$, Tirumalai S. Srivatsan ${ }^{2}$ and Manoj Gupta ${ }^{1, *}$ \\ 1 Department of Mechanical Engineering, National University of Singapore, 9 Engineering Drive 1, \\ Singapore 117576, Singapore; tvrlsravya@u.nus.edu (S.T.); a0096649@u.nus.edu (N.F.) \\ 2 Department of Mechanical Engineering, University of Akron, Akron, OH 44325, USA; tss1@uakron.edu \\ * Correspondence: mpegm@nus.edu.sg; Tel.: +65-6516-6358
}

Academic Editor: Hugo F. Lopez

Received: 13 October 2016; Accepted: 9 November 2016; Published: 11 November 2016

\begin{abstract}
Magnesium based nanocomposites, due to their excellent dimensional stability and mechanical integrity, have a lot of potential to replace the existing commercial $\mathrm{Al}$ alloys and steels used in aerospace and automotive applications. $\mathrm{Mg}$-Al alloys are commercially used in the form of $\mathrm{AZ}$ (magnesium-aluminum-zinc) and AM (magnesium-aluminum-manganese) series in automobile components. However, the $\mathrm{Mg}_{17} \mathrm{Al}_{12}$ phase in $\mathrm{Mg}$ - $\mathrm{Al}$ alloys is a low melting phase which results in a poor creep and high temperature performance of the alloys. Rare earth additions modify the phase and hence improve the properties of the materials. In this paper, $\mathrm{Ce}$ and nano $\mathrm{ZnO}$ particles were added to $\mathrm{Mg}$-Al alloys to attain a favorable effect on their properties. The developed materials exhibited promising properties in terms of thermal expansion coefficient (CTE), hardness, and tensile strength. Further, the $\mathrm{ZnO}$ addition refined the microstructure and helped in obtaining a uniform distribution, however without grain size refinement. The increased addition of $\mathrm{ZnO}$ and the improvement in the distribution led to an enhancement in the properties, rendering the materials suitable for a wide spectrum of engineering applications.
\end{abstract}

Keywords: Mg-3Al-0.4Ce alloy; nano ZnO particles; uniform distribution; strength

\section{Introduction}

The extraction and utilization of magnesium $(\mathrm{Mg})$ in significant amounts started only in the 20th century, despite the fact that the discovery of Mg by Sir H. Davy dates back to 1808 [1]. Mg, with a density of $1.738 \mathrm{~g} / \mathrm{cm}^{3}$, is one of the lightest engineering and structural metals available on the earth, with its density being about two-thirds that of aluminium and one-fourth that of steel [2]. Therefore, there is an increasing interest in the usage of $\mathrm{Mg}$ in certain engineering industries, specifically in the automobile, electronic, and aviation industries. In the above mentioned sectors, for material selection, weight of the components is one of the most crucial criteria, thus giving light metals such as $\mathrm{Mg}$ a lot of potential for applications. Besides low density, $\mathrm{Mg}$ based materials also display other beneficial properties such as specific mechanical strength, excellent damping capacity, good castability, machinability, thermal stability, weldability, and resistance to electromagnetic radiation [2]. However, despite these advantages, $\mathrm{Mg}$ has limited ductility under tensile deformation loads, poor elastic modulus, and low resistance to creep at high temperatures. As Mg has a Hexagonal Close Packed (HCP) crystal structure, at ambient temperatures, deformation is, thus, confined to a few modes such as basal slip and twinning. Due to fracture (transgranular and intergranular) at basal planes or twin zones, pure $\mathrm{Mg}$ shows a tendency for low ductility [1]. There is also a tension-compression yield asymmetry, and a significant difference in tensile and compressive yield strengths exhibited by $\mathrm{Mg}$, which narrows the opportunities of $\mathrm{Mg}$ in structural applications. To circumvent these limitations, 
$\mathrm{Mg}$ is alloyed with other elements, such as aluminium, zinc, zirconium, rare earths, etc., to improve strength, ductility, corrosion resistance, and other properties [1].

Among different alloying constituents, Al addition seems to have favourable effects on magnesium as it leads to increases in strength and ductility. Despite several extensive research studies and characterizations on magnesium-aluminium alloys, the main focus was laid on specific materials, such as AZ31, AZ61, and AZ91 [1]. Other potential alloying elements with Mg would be rare earth (RE) metals, which have been known for many years [1]. Furthermore, RE metals also are promising for increasing strength and ductility [3] when alloyed to Mg. However, one limitation of RE metals is the high cost, limiting their usage. Furthermore, the solubility of RE metals in Mg is not very high, hence, increase in the content of solute RE concentration reduces strength [4]. The results of literature studies showed that the addition of $0.4 \%$ Ce [5] yields the best properties of tensile strength and ductility and no research has been done to study the effect of reinforcement on $\mathrm{Mg}$-Al-Ce alloys. Furthermore, reinforcement with nano-particulates is also another possibility to improve the properties of $\mathrm{Mg}$. Previously reported literature shows that the improvement in strength and ductility was highest with the addition of nano-scale $\mathrm{ZnO}$ [6]. Furthermore, it may also be noted that the $\mathrm{ZnO}$ nanoparticle addition helped in reducing the tension-compression yield asymmetry (tensile yield strength/compressive yield strength) [6].

Accordingly, the aim of the current work was to develop Mg-Al-RE nanocomposites through the integration of aluminium, nano zinc oxide, and a rare earth element (Ce) using the Disintegrated Melt Deposition (DMD) technique followed by hot extrusion. Microstructure and mechanical properties are studied and critically analysed. The developed materials are expected to be promising in many engineering applications that include high performance automobile components such wheels (by replacing currently used AM60 alloys), transmission case, bumper beam, etc.

\section{Materials and Methods}

\subsection{Materials}

Mg was obtained in the form of turnings from Acros Organics, NJ, USA, with $99 \%$ purity. Al was obtained in powder form with a size of 7-15 $\mu \mathrm{m}$ from Alfa Aesar, with $99.5 \%$ purity. Ce was incorporated by using Mg-30 wt. \% Ce master alloy procured from Sunrelier Metal Co., Limited, Pudong, Shanghai, China. ZnO was obtained in the form of powder from Nanostructured and Amorphous Materials (Houston, TX, USA). The powder exhibited a particle size of less than $200 \mathrm{~nm}$ and an average particle size of $90 \mathrm{~nm}$.

\subsection{Primary Processing}

Synthesis of the Mg-3Al-0.4Ce alloy using magnesium turnings, Al powder, and Mg-Ce master alloy was carried out using the disintegrated melt deposition (DMD) technique [7]. Synthesis of the alloy involved heating the $\mathrm{Mg}$ turnings with the addition of respective weights of $\mathrm{Al}$ powder and $\mathrm{Mg}$-Ce master alloy in a graphite crucible to $750{ }^{\circ} \mathrm{C}$ using an electrical resistance furnace and an atmosphere of inert argon gas. The superheated melt was then stirred (at $465 \mathrm{rpm}$ for $5 \mathrm{~min}$ ) and bottom-poured into a steel mold (following disintegration by two jets of argon gas oriented normal to the melt stream). This technique displays the advantages of spray processing and conventional casting i.e., utilizing higher superheat temperatures and lower impinging gas jet velocities to produce the bulk composite material. The advantage of using this technique is to obtain a uniform distribution of reinforcements, fine equiaxed grains, and low porosity in the materials due to the rapid solidification of the atomized melt leading to an improvement in properties. An ingot of $40 \mathrm{~mm}$ diameter was obtained following the deposition stage. This technique was repeated for the other compositions, which contained $\mathrm{ZnO}$ nanoparticles. 


\subsection{Secondary Processing}

\subsubsection{Pre-Extrusion}

The $40 \mathrm{~mm}$ diameter ingots, obtained from casting, were machined down to a diameter of $36 \mathrm{~mm}$. Further, billets with lengths of approximately $45 \mathrm{~mm}$ were cut and machined.

\subsubsection{Extrusion}

The billets were, first, soaked at $400{ }^{\circ} \mathrm{C}$ for $1 \mathrm{~h}$ in a furnace, before extrusion. Extrusion was done at $350{ }^{\circ} \mathrm{C}$ on a 150 tonne hydraulic press. An extrusion ratio of 20.25:1 was used to produce rods of $8 \mathrm{~mm}$ diameter.

\subsubsection{Post-Extrusion}

After extrusion, the rods were machined to the required sample dimensions: dog bone shaped tensile test specimens with a gauge diameter of $5 \mathrm{~mm}$. Samples were also prepared for other characterisation tests.

\subsection{Characterisation}

\subsubsection{Density and Porosity}

Density measurements were performed in accordance with the Archimedes' principle on eight randomly selected samples taken from the extruded rods. The experimental density measurements involved weighing samples in air and in distilled water. Theoretical densities of materials were calculated assuming the samples are fully dense to measure the volume percentage of porosity in the end materials. The porosity was calculated by using the theoretical and experimental densities. An electronic balance (A\&D HM-202, Bradford, MA, USA) with an accuracy of $\pm 0.0001 \mathrm{~g}$ was used for all the measurements.

\subsubsection{Microstructure}

Microstructural characterization studies were conducted on metallographically polished extruded samples to investigate morphological characteristics of grains, reinforcement distribution, and interfacial integrity between the matrix and reinforcement. Picric acid was used as the etching solution. The sample was then analysed using the Leica DM2500 M metallographic optical microscope equipped with a Leica E3 digital colour camera (procured from Baldock, UK). Scion image analysis software was used to determine the grain size and morphology of the samples. The presence and distribution of the secondary phases as well as reinforcement was studied using the JEOL JSM-5600LV Scanning Electron Microscope (SEM) (procured from Tokyo, Japan).

\subsubsection{X-ray Diffraction}

X-ray diffraction (XRD) analysis of the samples was performed using the automated Shimadzu LAB-X XRD-6000 X-ray diffractometer (procured from Tokyo, Japan). The specimens, approximately $5 \mathrm{~mm}$ in height, were exposed to $\mathrm{CuK} \alpha$ radiation $(\lambda=1.54056 \AA)$ at a scanning speed of $2^{\circ} / \mathrm{min}$. The scanning range was $20^{\circ}-80^{\circ}$ for all samples. The graph intensity against $2 \theta$ ( $\theta$ represents the Bragg angle) was obtained, illustrating peaks at different Bragg angles. The Bragg angles corresponding to different peaks were noted, and the values of interplanar spacing (d-spacing) obtained from the computerized output were compared with the standard values from the Powder Diffraction File (PDF).

\subsubsection{Coefficient of Thermal Expansion}

Coefficient of Thermal Expansion (CTE) values were measured using a thermo mechanical analysis instrument "INSEIS TMA PT 1000LT" (procured from Tokyo, Japan). A heating rate of $5{ }^{\circ} \mathrm{C} / \mathrm{min}$ was 
maintained with an argon flow rate of $0.1 \mathrm{lpm}$. Using an alumina probe, the displacement of the test samples was measured as a function of temperature.

\subsubsection{Microhardness}

Microhardness measurements were obtained using the Shimadzu HMV automatic digital microhardness tester (procured from Tokyo, Japan) with a Vickers indenter (square-based pyramidal-shaped diamond indenter with a face angle of $136^{\circ}$ ). Cylindrical samples were prepared and polished. Tests were conducted in compliance with ASTM test method E384-11e1. A $25 \mathrm{~g}$ force load was applied with a dwell time of $15 \mathrm{~s}$. Three samples were prepared per composition and 10 readings were taken per sample for an accurate and consistent result. Indentations and the microhardness readings were recorded in Vickers Hardness number $\left(\mathrm{H}_{\mathrm{V}}\right)$.

\subsubsection{Tensile Test}

Tensile tests were performed using the MTS 810 machine (procured from Eden Prairie, MN, USA). Specimens of $5 \mathrm{~mm}$ diameter and $25 \mathrm{~mm}$ gauge length were prepared. Tests were conducted in compliance with ASTM test method E8M-13a. The crosshead speed was $2.54 \times 10^{-4} \mathrm{~m} / \mathrm{min}^{-1}$ (strain rate: $0.01 \mathrm{~min}^{-1}$ ). Five samples were tested per composition to obtain more accurate and consistent results. Fractured specimens were studied under SEM to analyse the fracture features.

\section{Results and Discussion}

\subsection{Density and Porosity}

The results of addition of $\mathrm{ZnO}$ nano-particulates show an increase in the density, but only marginally. While porosity values do not manifest any particular trend, the values remained relatively insignificant. The results for density and porosity can be found in Table 1. Within the synthesised materials, a positive trend was noticed with the addition of $\mathrm{ZnO}$ nano-particulates in terms of density. This is expected to be due to the high density of $\mathrm{ZnO}(5.61 \mathrm{~g} / \mathrm{cc})$ as compared to that of $\mathrm{Mg}$. Furthermore, the addition of increasing amounts of $\mathrm{ZnO}$ nano-particulates increased the porosity of the alloy. The same trend was noticed in other studies on nano-composites [7]. The highest porosity was recorded for the $\mathrm{Mg}-3 \mathrm{Al}-0.4 \mathrm{Ce}-2.5 \mathrm{ZnO}$ nanocomposite. This is due to the possible clustering effects caused by the increased addition of nano-reinforcements (a limitation of the casting technique). Nevertheless, the absolute porosity values are relatively low, with the highest recorded porosity value being about $1 \%$. Thus, obtaining nanocomposites with $<1 \%$ porosity was achieved and is accredited to the secondary processing (extrusion and the extrusion ratio).

Table 1. Density, Porosity, and Grain size results.

\begin{tabular}{ccccc}
\hline Composition & $\begin{array}{c}\text { Experimental } \\
\text { Density }\left(\mathbf{g} / \mathbf{c m}^{3}\right)\end{array}$ & $\begin{array}{c}\text { Theoretical } \\
\text { Density }\left(\mathbf{g} / \mathbf{c m}^{3}\right)\end{array}$ & Porosity (\%) & Grain Size $(\mu \mathrm{m})$ \\
\hline $\mathrm{Mg}-3 \mathrm{Al}-0.4 \mathrm{Ce}$ & $1.759 \pm 0.013$ & 1.762 & 0.201 & $6.5 \pm 1.5$ \\
$\mathrm{Mg}-3 \mathrm{Al}-0.4 \mathrm{Ce}-1.5 \mathrm{ZnO}$ & $1.779 \pm 0.012(\uparrow 1.13 \%)^{1}$ & 1.781 & 0.120 & $6.4 \pm 1.5$ \\
$\mathrm{Mg}-3 \mathrm{Al}-0.4 \mathrm{Ce}-2 \mathrm{ZnO}$ & $1.783 \pm 0.013(\uparrow 1.36 \%)^{1}$ & 1.787 & 0.235 & $6.1 \pm 1.5$ \\
$\mathrm{Mg}-3 \mathrm{Al}-0.4 \mathrm{Ce}-2.5 \mathrm{ZnO}$ & $1.774 \pm 0.028(\uparrow 0.85 \%)^{1}$ & 1.794 & 1.080 & $6.0 \pm 1.6$ \\
\hline
\end{tabular}

\subsection{Microstructure/Phase Analysis}

\subsubsection{Grain Size Analysis}

Nearly similar grain morphology was noticed when the samples were studied under the optical microscope. The results and images of the grain size and morphology are shown in Table 1 and 
Figure 1a-d. The addition of $\mathrm{ZnO}$ did not affect the grain size of the monolithic alloy, considering the standard deviation.

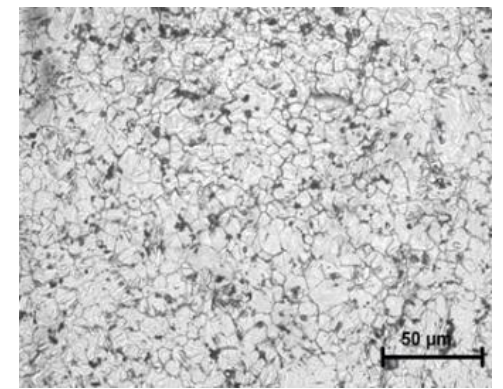

(a)

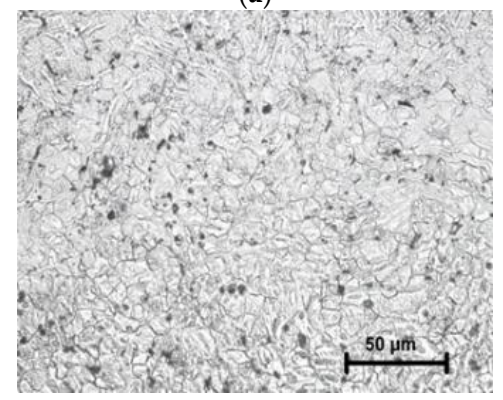

(c)

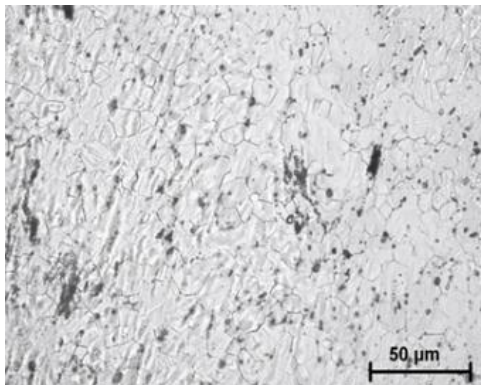

(b)

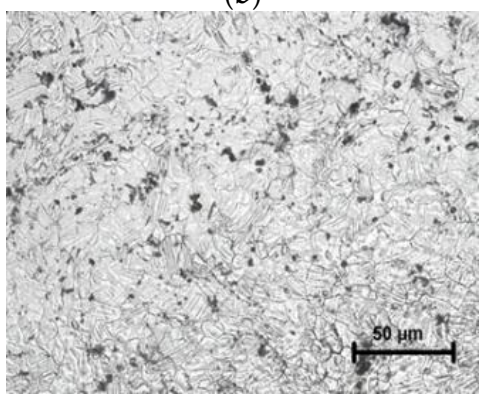

(d)

Figure 1. Images observed under an optical microscope for: (a) Mg-3Al-0.4Ce; (b) Mg-3Al-0.4Ce-1.5ZnO; (c) Mg-3Al-0.4Ce-2ZnO and (d) Mg-3Al-0.4Ce-2.5ZnO.

\subsubsection{Microstructure Analysis}

Figure $2 \mathrm{a}-\mathrm{d}$ shows the secondary phase distribution in the alloy and the nanocomposites. The images indicate the reduced size of the secondary phases and the improved phase and reinforcement distribution with an increase in the amount of $\mathrm{ZnO}$ particles.

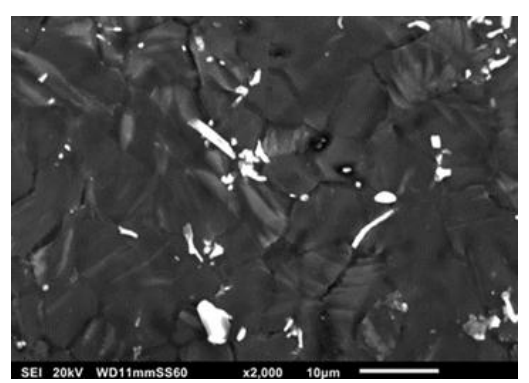

(a)

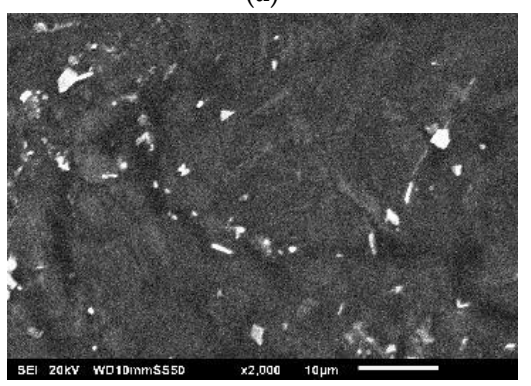

(c)

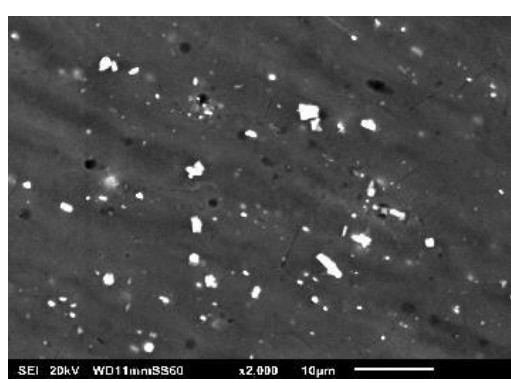

(b)

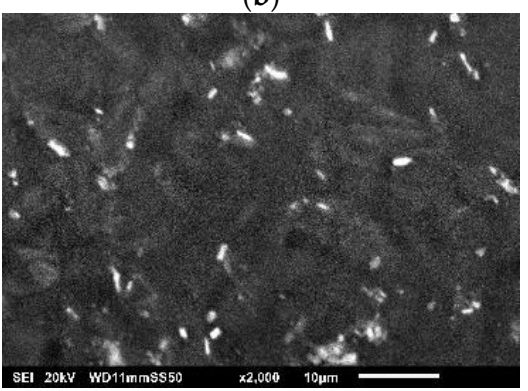

(d)

Figure 2. Images observed under SEM for:

(a) Mg-3Al-0.4Ce;

(b) $\mathrm{Mg}-3 \mathrm{Al}-0.4 \mathrm{Ce}-1.5 \mathrm{ZnO}$; (c) $\mathrm{Mg}-3 \mathrm{Al}-0.4 \mathrm{Ce}-2 \mathrm{ZnO}$ and (d) $\mathrm{Mg}-3 \mathrm{Al}-0.4 \mathrm{Ce}-2.5 \mathrm{ZnO}$. 


\subsubsection{Phase Analysis}

The XRD patterns confirmed the existence of secondary phases as shown in Figure 3. The peaks seen in the obtained patterns are correlated with the standard diffraction patterns obtained from the Powder Diffraction File data (PDF). The following phases were confirmed to be present in all the synthesized compositions, in varying intensities: $\alpha-\mathrm{Mg}, \mathrm{Mg}_{17} \mathrm{Al}_{12}, \mathrm{Al}_{11} \mathrm{Ce}_{3},(\mathrm{Al}, \mathrm{Mg})_{2} \mathrm{Ce}$.

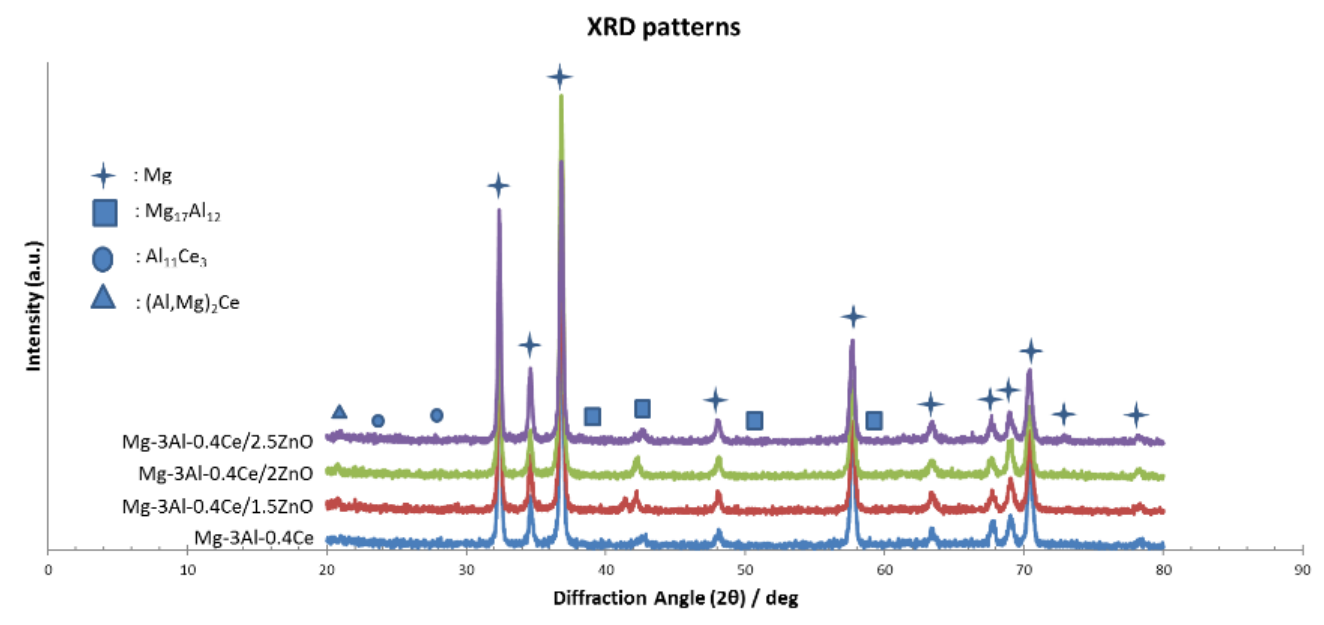

Figure 3. X-ray diffraction patterns.

No peaks corresponding to the Mg-Ce intermetallic phases were observed from the XRD patterns. This is ascribed to be due to the greater affinity of Ce towards $\mathrm{Al}$ [8], therefore, forming a $\mathrm{Al}_{11} \mathrm{Ce}_{3}$ phase instead of a Mg-Ce phase. From the SEM images in Figure 2, for alloy and nanocomposites, blocky shaped structures and rod-like structures were observed in the matrix. Spherical structures were also observed only in the case of nanocomposites.

From the energy dispersive spectroscopy (EDS) results in Figure 4, the following inferences are made: (i) The matrix correspond to Mg-Al solid solution; (ii) blocky shaped structures correspond to the $\mathrm{Mg}_{17} \mathrm{Al}_{12}$ phase (iii) rod-like structures are a combination of a phase containing $\mathrm{Mg}$, $\mathrm{Al}$, and Ce. While this could be either the $\mathrm{Al}_{11} \mathrm{Ce}_{3}$ phase or $(\mathrm{Al}, \mathrm{Mg})_{2} \mathrm{Ce}$ phase, previous research has shown that $\mathrm{Al}_{11} \mathrm{Ce}_{3}$ phase has a needle-like structure [9] and is the more dominant phase compared to $(\mathrm{Al}, \mathrm{Mg})_{2} \mathrm{Ce}[10]$. Furthermore, $\mathrm{XRD}$ results also suggests that more peaks were observed for $\mathrm{Al}_{11} \mathrm{Ce}_{3}$ phase. Thus, this rod-like structure could be the $\mathrm{Al}_{11} \mathrm{Ce}_{3}$ phase. Further; (iv) the spherical structures are noted to be $\mathrm{ZnO}$ nano-particles. Also, these structures were detected only on the materials containing the $\mathrm{ZnO}$ particles. Furthermore, no evident peaks of $\mathrm{ZnO}$ were observed in the XRD patterns. This is due to the inability of XRD to detect nano-length scale particles in low volume fractions.

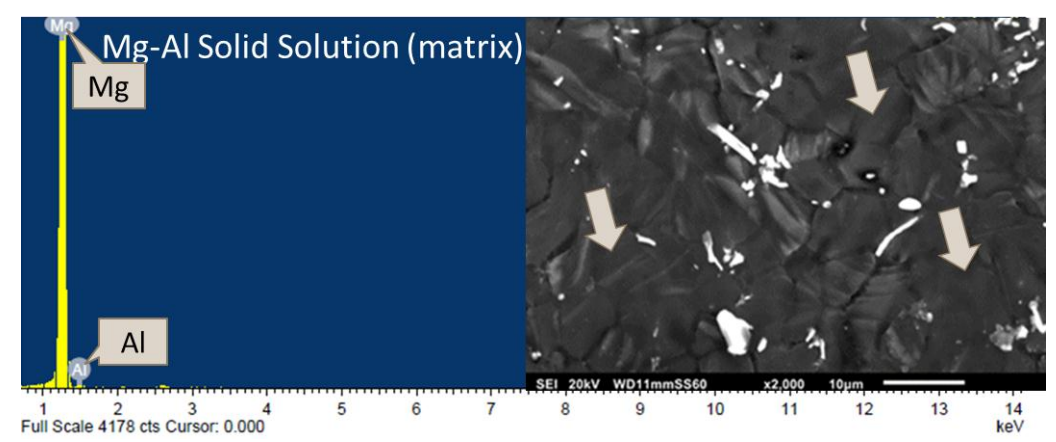

(a)

Figure 4. Cont. 


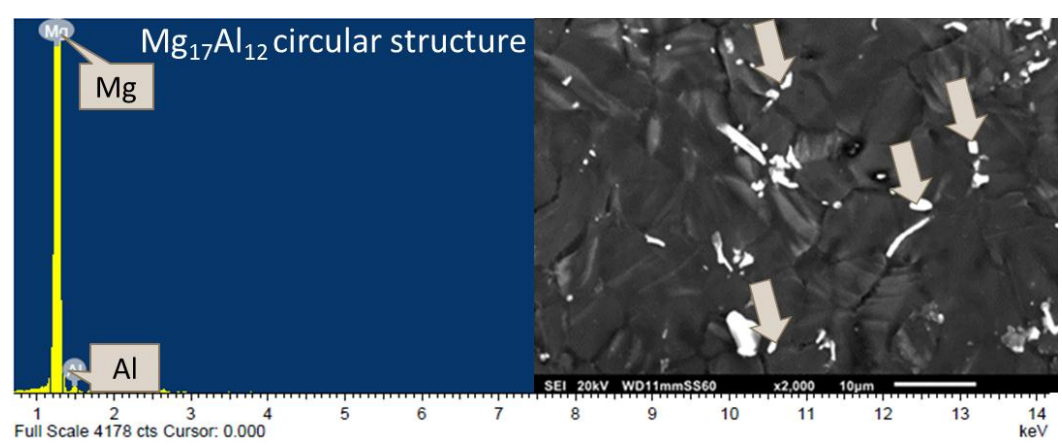

(b)

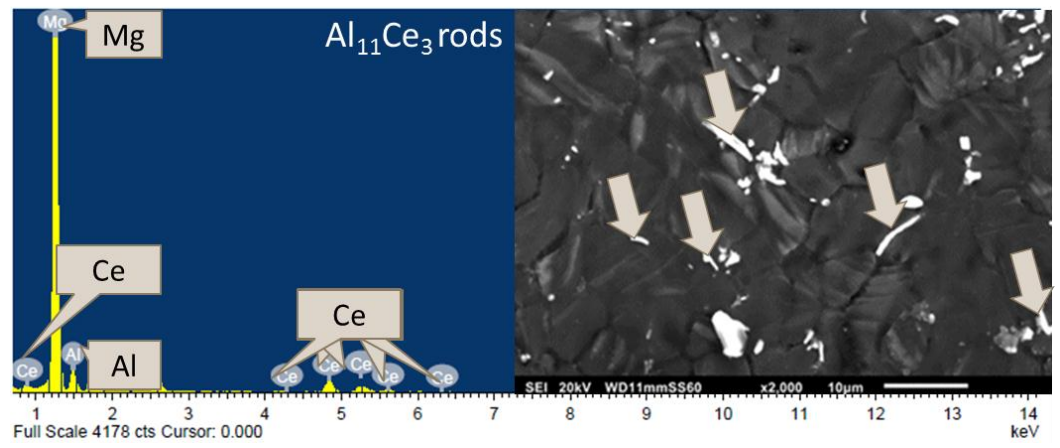

(c)

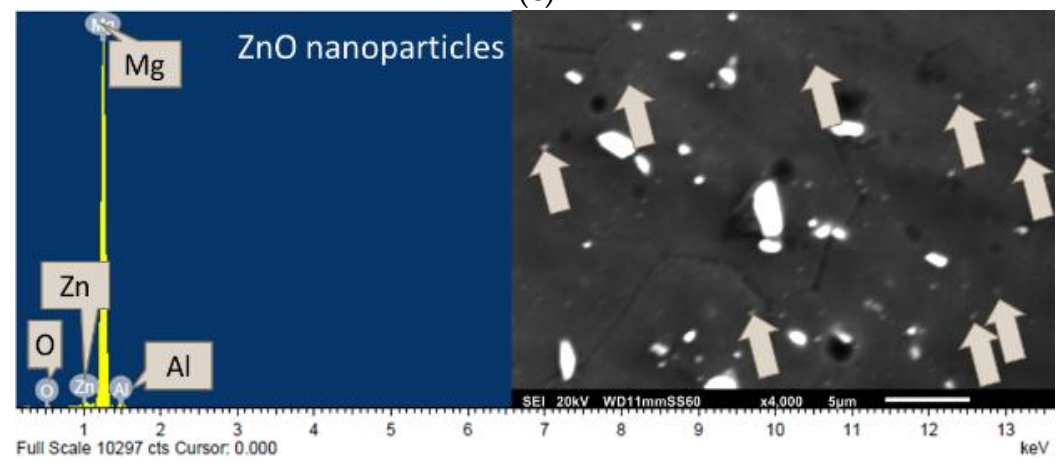

(d)

Figure 4. EDS analysis of the phases (a) $\mathrm{Mg}$ - $\mathrm{Al}$ matrix; (b) circular $\mathrm{Mg}_{17} \mathrm{Al}_{12}$ phase; (c) rod shaped $\mathrm{Al}_{11} \mathrm{Ce}_{3}$ phase and (d) $\mathrm{ZnO}$ nanoparticles (in a high magnification image of $\mathrm{Mg}-3 \mathrm{Al}-0.4 \mathrm{Ce}-1.5 \mathrm{ZnO}$ showing nano-particle distribution).

Thus, from the microstructural characterization of the Mg-3Al-0.4Ce alloy and its $\mathrm{ZnO}$ reinforced nanocomposites, the following points are to be factored in: (a) no drastic change in the grain morphology or grain size among the alloy and nanocomposites and (b) a more uniform distribution of the hard secondary phases and $\mathrm{ZnO}$ nano-particulates in the nanocomposites.

\subsection{Coefficient of Thermal Expansion (CTE)}

Thermal expansion refers to the tendency to change shape in response to a change in temperature, occurring through heat transfer. The lesser the CTE value, the lesser the tendency for the material to change shape when the temperature is increased. Thus, a material with lower CTE values indicates a thermally stable material. The addition of $\mathrm{Al}$ and Ce corresponded to a drop in the CTE value of $\mathrm{Mg}$. Comparing Mg-Al-0.4Ce with $\mathrm{Mg}-3 \mathrm{Al}-0.4 \mathrm{Ce}-1.5 \mathrm{ZnO}$, a further decrease in CTE value was noticed. However, when the wt $\%$ of $\mathrm{ZnO}$ nano-particles increased, the CTE values increased. Nevertheless, the addition of $\mathrm{ZnO}$ particles resulted in overall lower CTE values and thereby, more thermally stable 
materials in contrast with the monolithic alloy. Results of the CTE are shown Table 2. The obtained results are due to the lower CTE value of $\mathrm{ZnO}$ as compared to that of $\mathrm{Mg}$.

Table 2. CTE results.

\begin{tabular}{cc}
\hline Composition & CTE $\left(\mu \mathbf{K}^{-\mathbf{1}}\right)$ \\
\hline Mg-3Al-0.4Ce & $25.52 \pm 0.8$ \\
$\mathrm{Mg}-3 \mathrm{Al}-0.4 \mathrm{Ce}-1.5 \mathrm{ZnO}$ & $22.03 \pm 1.0$ \\
$\mathrm{Mg}-3 \mathrm{Al}-0.4 \mathrm{Ce}-2 \mathrm{ZnO}$ & $24.16 \pm 2.0$ \\
$\mathrm{Mg}-3 \mathrm{Al}-0.4 \mathrm{Ce}-2.5 \mathrm{ZnO}$ & $24.36 \pm 0.6$ \\
\hline
\end{tabular}

\subsection{Mechanical Properties}

\subsubsection{Microhardness}

The microhardness of Mg-3Al-0.4Ce alloy is seen to be much higher as compared to that of pure $\mathrm{Mg}$ [5] and commercially available AZ31B [11]. This is due to the addition of a rare earth element. Nayyeri et al. [12] reported an increase in hardness when RE metals were added to $\mathrm{Mg}-\mathrm{Al}$ alloys, due to the Al-RE intermetallic phase formation. Further, the increasing addition of $\mathrm{ZnO}$ nanopartices progressively increased the microhardness of the nanocomposites (Table 3). This is due to the existence of harder $\mathrm{ZnO}$ particles that can resist deformation under indentation loads [13].

Table 3. Tensile test results.

\begin{tabular}{ccccc}
\hline Composition & $\begin{array}{c}\text { Microhardness } \\
\mathbf{( H v )}\end{array}$ & $\begin{array}{c}\mathbf{0 . 2 \%} \text { Offset Tensile } \\
\text { Yield Strength (MPa) }\end{array}$ & $\begin{array}{c}\text { Ultimate Tensile } \\
\text { Strength (MPa) }\end{array}$ & Fracture Strain (\%) \\
\hline $\mathrm{Mg}-3 \mathrm{Al}-0.4 \mathrm{Ce}$ & $105 \pm 4$ & $144 \pm 8$ & $232 \pm 11$ & $17 \pm 1$ \\
$\mathrm{Mg}-3 \mathrm{Al}-0.4 \mathrm{Ce}-1.5 \mathrm{ZnO}$ & $113 \pm 3(\uparrow 7.6 \%)^{1}$ & $157 \pm 8(\uparrow 9 \%)^{1}$ & $263 \pm 8(\uparrow 13 \%)^{1}$ & $17 \pm 5$ \\
$\mathrm{Mg}-3 \mathrm{Al}-0.4 \mathrm{Ce}-2 \mathrm{ZnO}$ & $144 \pm 4(\uparrow 37.1 \%)^{1}$ & $173 \pm 11(\uparrow 20 \%)^{1}$ & $288 \pm 11(\uparrow 24 \%)^{1}$ & $18 \pm 2$ \\
$\mathrm{Mg}-3 \mathrm{Al}-0.4 \mathrm{Ce}-2.5 \mathrm{ZnO}$ & $161 \pm 5(\uparrow 53.3 \%)^{1}$ & $180 \pm 7(\uparrow 25 \%)^{1}$ & $294 \pm 9(\uparrow 27 \%)^{1}$ & $15 \pm 2$ \\
$\mathrm{Mg}-3 \mathrm{Al}-0.2 \mathrm{Ce}[8]$ & - & 120 & 235 & - \\
$\mathrm{Mg}-3 \mathrm{Al}-0.5 \mathrm{Ce}[8]$ & - & 125 & 230 & - \\
\hline \multicolumn{4}{r}{${ }^{1}(\uparrow x \%)$ corresponds to an increase in the respective property by $x \%$ as compared to the monolithic alloy. }
\end{tabular}

\subsubsection{Tensile Properties}

A trend similar to that of the microhardness results was observed for the results of the tensile tests. An increase in the $0.2 \%$ offset yield strength and ultimate tensile strength was observed with the progressive addition of $\mathrm{ZnO}$ to the $\mathrm{Mg}-3 \mathrm{Al}-0.4 \mathrm{Ce}$ alloy. The addition of $\mathrm{ZnO}$ displayed no significant effect on the ductility. The overall tensile response assessed in terms of the energy absorption capability prior to failure remained superior in the case of the nanocomposites. The results are found in Table 3 and Figure 5. When compared to the previously reported results on $\mathrm{Mg}-3 \mathrm{Al}-0.2 \mathrm{Ce}$ and $\mathrm{Mg}-3 \mathrm{Al}-0.5 \mathrm{Ce}$ alloys [8] (similar processing conditions), it is observed that the materials synthesized in this study possess superior strengths. Within the nanocomposites, the fracture strain and energy absorption values increased from Mg-3Al-0.4Ce to Mg-3Al-0.4Ce-2ZnO and decreased for Mg-3Al-0.4Ce-2.5ZnO. This could be due to a clustering effect of $\mathrm{ZnO}$ nanoparticles [14], as well as the increased porosity as seen in Table 1 for the $\mathrm{Mg}-3 \mathrm{Al}-0.4 \mathrm{Ce}-2.5 \mathrm{ZnO}$ nanocomposite. Furthermore, an interesting observation from the curves is that all the materials fractured at (or before realizing) their ultimate tensile strengths, i.e., they had not undergone any deformation after reaching the peak values. This shows that the ultimate failure has occurred at (or before) the peak stress. This occurs when the plastic strain at any point in the material reaches the maximum value. The common stress concentration sites in all the materials, in this study, are the rod shaped $\mathrm{Al}_{11} \mathrm{Ce}_{3}$ structures. These rods seemed to act as the stress concentration sites, i.e., sites for continued local stresses. When the local stress at these sites reach the 
threshold stress, the materials begin to fail at these sites. Thus, the rod shaped $\mathrm{Al}_{11} \mathrm{Ce}_{3}$ is responsible for the materials exhibiting this phenomenon.

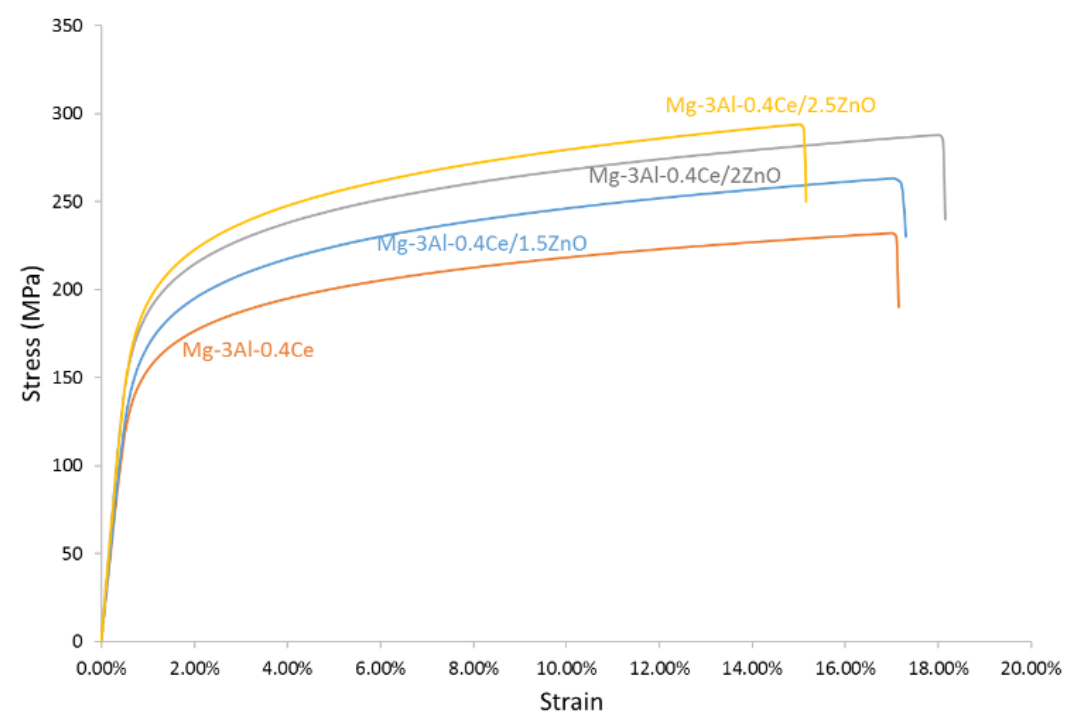

Figure 5. Engineering tensile stress strain curves.

\subsubsection{Fractography}

The microscopic fracture features of the samples fractured in the tensile test are shown in Figure 6. These images revealed pronounced ductile features due to plastic deformation. Typically, magnesium materials exhibit cleavage features which are suggestive of their inability to deform plastically (due to the HCP crystal structure). However, in the current study, the developed Mg-3Al-0.4Ce alloy and its $\mathrm{ZnO}$ reinforced nanocomposites showed noticeable ductile features representing the occurrence of pronounced plastic deformation, thus validating the tensile test results.

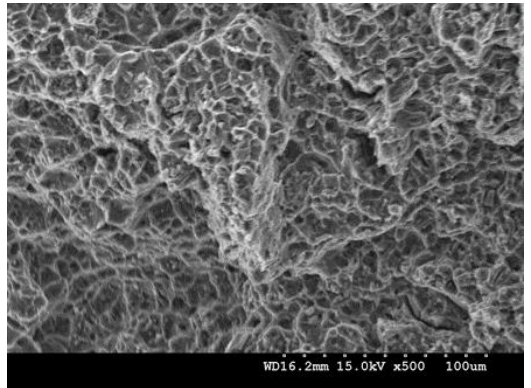

(a)

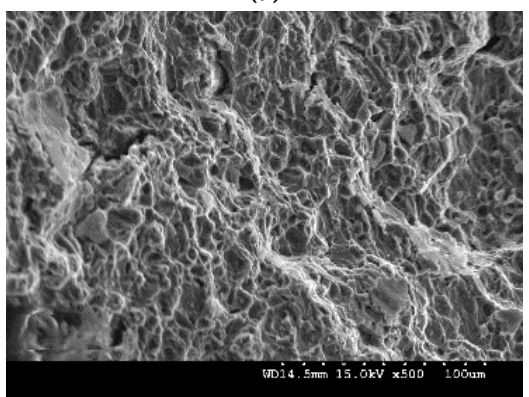

(c)

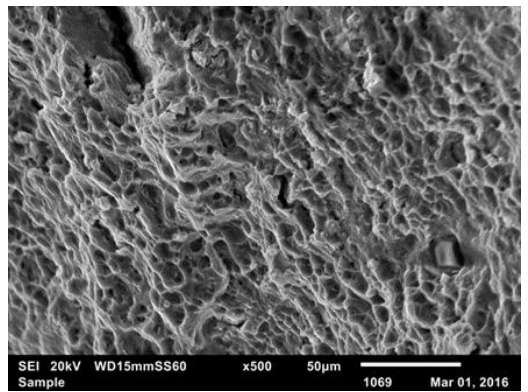

(b)

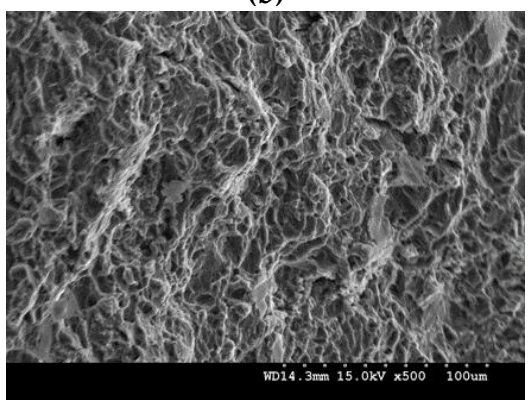

(d)

Figure 6. Fracture surfaces of the (a) Mg-3Al-0.4Ce alloy; (c) $\mathrm{Mg}-3 \mathrm{Al}-0.4 \mathrm{Ce}-2 \mathrm{ZnO}$ and (d) $\mathrm{Mg}-3 \mathrm{Al}-0.4 \mathrm{Ce}-2.5 \mathrm{ZnO}$ nanocomposites.

(b) $\mathrm{Mg}-3 \mathrm{Al}-0.4 \mathrm{Ce}-1.5 \mathrm{ZnO}$; 


\section{Conclusions}

Synthesis of the Mg-3Al-0.4Ce alloy and its $\mathrm{ZnO}$ nano-particulate reinforced nanocomposites was carried out using the DMD technique followed by hot extrusion. The microstructural and mechanical properties were studied. With the current findings, the following can be concluded:

1. The processing methodology used in this study is capable of synthesizing the Mg-3Al-0.4Ce alloy and its nanocomposites with porosities restricted to $\sim 1 \%$.

2. The addition of $\mathrm{ZnO}$ nanoparticles reduced the CTE of the Mg-3Al-0.4Ce alloy, resulting in more dimensionally stable nanocomposites.

3. The addition of $\mathrm{ZnO}$ nano-particulates corresponded with the increase in the microhardness of the Mg-3Al-0.4Ce alloy. A maximum microhardness was realized in the case of the $\mathrm{Mg}-3 \mathrm{Al}-0.4 \mathrm{Ce} / 2.5 \mathrm{ZnO}$ nanocomposite, with a value of $161 \mathrm{Hv}$.

4. The addition of an increasing amount of $\mathrm{ZnO}$ nanoparticles led to an increase in the $0.2 \%$ offset yield strength and ultimate tensile strength, while strain to fracture remained unaffected. A maximum yield strength of $180 \mathrm{MPa}$ and ultimate tensile strength of $294 \mathrm{MPa}$ was achieved for the $\mathrm{Mg}-3 \mathrm{Al}-0.4 \mathrm{Ce} / 2.5 \mathrm{ZnO}$ nanocomposite.

5. These superior mechanical properties, achieved with the addition of the $\mathrm{ZnO}$ nanoparticles, are attributed to the uniform distribution of the secondary phases and the presence of $\mathrm{ZnO}$ reinforcement.

Acknowledgments: This work was supported by the Singapore Ministry of Education Academic Research Funding (grant number WBS\# R-265-000-498-112).

Author Contributions: Sravya Tekumalla and Manoj Gupta conceived and designed the experiments; Sravya Tekumalla and Najib Farhan performed the experiments, Sravya Tekumalla, Manoj Gupta, and Tirumalai S. Srivatsan analyzed the data, and all the authors wrote the paper.

Conflicts of Interest: The authors declare no conflict of interest.

\section{References}

1. King, J.F. Magnesium: Commodity or exotic? Mater. Sci. Technol. 2007, 23, 1-14. [CrossRef]

2. Alam, M.E.; Han, S.; Nguyen, Q.B.; Hamouda, A.M.S.; Gupta, M. Development of new magnesium based alloys and their nanocomposites. J. Alloy. Compd. 2011, 509, 8522-8529. [CrossRef]

3. Tekumalla, S.; Seetharaman, S.; Almajid, A.; Gupta, M. Mechanical Properties of Magnesium-Rare Earth Alloy Systems: A Review. Metals 2015, 5, 1. [CrossRef]

4. Rokhlin, L.L. Structure and properties of alloys of the Mg-REM system. Met. Sci. Heat Treat. 2006, 48, 487-490. [CrossRef]

5. Tekumalla, S.; Seetharaman, S.; Bau, N.Q.; Wong, W.L.E.; Goh, C.S.; Shabadi, R.; Gupta, M. Influence of Cerium on the Deformation and Corrosion of Magnesium. J. Eng. Mater. Technol. 2016, 138, 031011. [CrossRef]

6. Sankaranarayanan, S.; Nayak, U.P.; Sabat, R.; Suwas, S.; Almajid, A.; Gupta, M. Nano-ZnO particle addition to monolithic magnesium for enhanced tensile and compressive response. J. Alloy. Compd. 2014, 615, 211-219. [CrossRef]

7. Gupta, M.; Wong, W.L.E. Magnesium-based nanocomposites: Lightweight materials of the future. Mater. Charact. 2015, 105, 30-46. [CrossRef]

8. Luo, A.A.; Wu, W.; Mishra, R.K.; Jin, L.; Sachdev, A.K.; Ding, W. Microstructure and Mechanical Properties of Extruded Magnesium-Aluminum-Cerium Alloy Tubes. Metall. Mater. Trans. A 2010, 41, 2662-2674. [CrossRef]

9. Song, Y.L.; Liu, Y.H.; Wang, S.H.; Yu, S.R.; Zhu, X.Y. Effect of cerium addition on microstructure and corrosion resistance of die cast AZ91 magnesium alloy. Mater. Corros. 2007, 58, 189-192. [CrossRef]

10. Zhang, J.; Leng, Z.; Zhang, M.; Meng, J.; Wu, R. Effect of Ce on microstructure, mechanical properties and corrosion behavior of high-pressure die-cast Mg-4Al-based alloy. J. Alloy. Compd. 2011, 509, 1069-1078. [CrossRef] 
11. Nguyen, Q.B.; Gupta, M. Increasing significantly the failure strain and work of fracture of solidification processed AZ31B using nano- $\mathrm{Al}_{2} \mathrm{O}_{3}$ particulates. J. Alloy. Compd. 2008, 459, 244-250. [CrossRef]

12. Nayyeri, M.J.; Ganjkhanlou, Y.; Kolahi, A.; Jamili, A.M. Effect of Ca and Rare Earth Additions on the Texture, Microhardness, Microstructure and Structural Properties of As-Cast Mg-4Al-2Sn Alloys. Trans. Indian Inst. Met. 2014, 67, 469-475. [CrossRef]

13. Yahya, N.; Puspitasari, P.; Latiff, N.R.A. Characterization and Development of Biosystems and Biomaterials; Springer: Berlin/Heidelberg, Germany, 2013; pp. 9-32.

14. Zhaoxu, D.; Daining, F.; Kah, S.A. On the effect of nano-particle clustering on toughening of nano-composite ceramics. Acta Mech. Sin. 2002, 18, 146-158. [CrossRef]

(C) 2016 by the authors; licensee MDPI, Basel, Switzerland. This article is an open access article distributed under the terms and conditions of the Creative Commons Attribution (CC-BY) license (http:/ / creativecommons.org/licenses/by/4.0/). 